\title{
De las representaciones de las (pos)guerras centroamericanas en la narrativa costarricense contemporánea ${ }^{1}$
}

\section{Verónica Ríos Quesada ${ }^{2}$}

Instituto Tecnológico de Costa Rica, Costa Rica

\section{resumen}

Las novelas Te llevaré en mis ojos de Rodolfo Arias y Limón Reggae de Anacristina Rossi representan tanto las guerras como la posguerra en Centroamérica. Inauguran un cronotopo: costarricenses en la experiencia revolucionaria centroamericana desde una mirada femenina no ligada a una subjetividad heroica. Sin embargo, en esas obras no se logra mostrar a la sociedad costarricense en el contexto transnacional, por lo que se refuerzan los cronotopos escindidos con respecto a Centroamérica que caracterizan al imaginario simbólico costarricense.

\section{abstract}

The novels Te llevaré en mis ojos by Rodolfo Arias and Limón Reggae by Anacristina Rossi represent both the wars and the postwar period in Central America. They establish a chronotope: Costa Ricans in the revolutionary Central American experience from a feminine perspective which is not connected to heroic subjectivity. However, in these novels the Costa Rican context is not shown in a multinational context, thus reinforcing split chronotopes concerning Central America which characterize the Costa Rican symbolic imaginary.

Palabras clave: novela costarricense contemporánea, literatura de posguerra en America Central, cronotopos costarricenses

Keywords: contemporary Costa Rican novel, postwar literature in Central America, Costa Rican chronotopes

1 Ponencia presentada en el XX Congreso Internacional de Literatura Centroamericana (ciLca) 2012. Recibido: 7 de febrero de 2011; aceptado: 12 de marzo de 2011.

2 Correo electrónico: veroriosq@gmail.com 
Sostiene Arturo Arias que la narratividad regional de la posguerra corresponde a la fase neoliberal y «es llamada a ofrecer pautas para potencialmente transformar las dimensiones de la lucha contra las consecuencias implícitas de las políticas neoliberales en la región» (A. Arias). Desde ese punto de vista, rearticular y ficcionalizar la historia reciente de Centroamérica es una estrategia que combate la homogenización generada por estas políticas y contrarresta la pérdida de memoria cultural.

A finales de la década de 1990 se publicó un considerable número de novelas costarricenses que narran las experiencias revolucionarias centroamericanas. Algunas de ellas: Cruz de olvido de Carlos Cortés (1999), Desconciertos en un jardín tropical de Magda Zavala (1999), Los ojos del antifaz de Adriano Corrales (2007), Limón Reggae de Anacristina Rossi (2007) y Te llevaré en mis ojos de Rodolfo Arias (2007). Estas novelas inauguran un cronotopo difícil de articular en el imaginario simbólico costarricense, pues históricamente éste se ha modelado estableciendo grandes distancias con respecto al Otro centroamericano y autodefiniéndose como oasis de paz en una región convulsa. En contraposición a los estereotipos de «Suiza Centroamericana» o de que Costa Rica es el país más feliz del mundo, los textos mencionados apuntan hacia miedos y silencios colectivos.

De ese grupo, me interesa destacar Te llevaré en mis ojos de Rodolfo Arias y Limón Reggae de Anacristina Rossi, publicadas en 2007. Son dos novelas históricas catárticas ${ }^{3}$, que se destacan por su extensión en la temporalidad histórica a la que se refieren. Se extienden respectivamente veinte años en el caso de Arias (1970-1990) ${ }^{4}$ y treinta (1970-2000), en el de Rossi. Representan tanto la guerra como la posguerra. Por una parte, se inaugura un cronotopo: la participación de costarricenses en la experiencia revolucionaria centroamericana desde una mirada femenina no ligada a una subjetividad

\footnotetext{
3 Amalia Chaverri ubica a Cruz de olvido como novela catártica (208), al igual que las Limón Reggae de Rossi (212). Chaverri (207-208, 212).

4 La novela comienza en 1970, cuando Lucía tenía unos quince años (Rossi, Apartado 1).
} 
heroica. Por otra parte, no se termina de hilar a la sociedad costarricense en el contexto transnacional. En diferentes grados, nos encontramos una vez más frente a los cronotopos escindidos que caracterizan al imaginario simbólico costarricense.

\section{Contexto histórico-literario}

En estas novelas de Rossi y Arias, se representan tanto la utopía como el desencanto en torno a las luchas revolucionarias de Centroamérica desde Costa Rica ${ }^{5}$. La producción literaria de la década de 1980 en este país, a contracorriente de la explosión testimonial de esa década en Centroamérica ${ }^{6}$, evidencia la negación del presente. En palabras del escritor Carlos Cortés, los literatos le tuvieron «horror a la realidad». Se refugiaron en los mitos nacionalistas y no quisieron/pudieron problematizar la crisis económica costarricense ni la regional, ni el impacto de la economía marca Reagan o la llegada del neoliberalismo. Se escudaron bajo la premisa de que en Costa Rica no hay nada sobre qué escribir?

Siguiendo el razonamiento de Cortés, los escritores no se percataron de la muerte del modelo socialdemócrata que sustentaba las

5 Sobre la solidaridad con la revolución sandinista y la admiración que suscitó en Costa Rica la lucha contra Somoza, también se puede mencionar la novela de Pinto El eco de los pasos, en la que se relaciona la guerra civil del 48 con el abandono de los ideales del presente de los años setenta. Asimismo, otra novela que ficcionaliza la experiencia revolucionaria es la del salvadoreño radicado en Estados Unidos de Róger Lindo, El perro en la niebla (2006), mientras que Huracán corazón del cielo (1995) del guatemalteco-nicaragüense Franz Galich y La ceremonia del mapache (1996) del guatemalteco Otoniel Martínez abordan distintas dimensiones de la lucha armada guatemalteca. Esta proliferación de novelas acerca de diversas caras de la experiencia revolucionaria centroamericana apunta hacia la normalización de la violencia, ya no exclusivamente en el nivel de la diégesis, sino también en el incipiente campo literario centroamericano de finales del siglo xx e inicios del siglo xxi (Mackenbach y Ortiz Wallner, 85).

6 Señala Rodríguez que la década de los ochenta es una de las más productivas discursivamente en El Salvador. El testimonio fue usado por muchos para hablar estratégicamente y críticamente acerca del poder (Rodríguez, 79).

7 Carlos Cortés, «El fin de mito de la igualdad. Breve panfleto contra el «aprismo» literario: Para una sociología de la literatura postsocialdemócrata», Literaturas centroamericanas hoy: desde la dolorosa cintura de America, Karl Kohut y Werner Mackenbach (Eds.) (Madrid, Frankfurt: Iberoamericana; Vervuert, 2003) 147-53 (147-148). 
políticas culturales. El mundo literario empezaba a regirse únicamente por leyes del mercado, ni de los resquebrajamientos del mito de la igualdad perpetuado por dicho modelo ${ }^{8}$. William Robinson lo expresa claramente: «Costa Rica se integra a la economía global en términos parecidos a las de la región, el que haya habido o no una guerra civil de por medio no cambia el resultado global». De hecho, indica Robinson, Costa Rica abrió el camino para la agenda transnacional en Centroamérica. El deterioro ha sido más gradual, pero no por eso deja de ser contundente 9 .

Antes de pasar al análisis, quisiera hacer hincapié en la inexistencia de precedentes con respecto a una «narrativa de los procesos revolucionarios centroamericanos» en la producción literaria costarricense. No hay una novelística anterior al grupo de textos mencionado en la introducción, escrita por guerrilleros, o narraciones testimoniales (testimonios de participantes así como novelas testimoniales), menos aún novelas disidentes, las tres categorías que Héctor Leyva asocia con la narrativa de tales procesos (Leyva 1995, citado por Mackenbach y Ortiz Wallner) ${ }^{10}$.

\section{Mirada femenina-compasiva, nostálgica}

Retomando las novelas de Rossi y Arias, construir personajes que vinculan a la sociedad costarricense con las revoluciones y el desencanto de la posguerra centroamericana es un reto de gran magnitud. A diferencia de las novelas de Horacio Castellanos Moya o Franz Galich, estos textos evidentemente no pueden convertirse en «alegoría de la situación de toda una generación de centroamericanos

8 Cortés señala que, si bien se rompió ese molde literariamente hablando a fines de los setenta con la trilogía de la «revolución traicionada» (Los vencidos de Hurtado, El eco de los pasos de Pinto y Final de calle de Quince Duncan), durante los ochenta no se continúa por esa línea (Cortés, 147-53).

9 William I. Robinson, Transnational Conflicts: Central America, Social Change and Globalization (Londres, Nueva York: VERSO, 2003) 132-146.

10 Werner Mackenbach y Alexandra Ortiz Wallner. «(De)formaciones: violencia y narrativa en Centroamérica», IberoamericanaALEP 8.32 (2008): 81-97 (84). 
que no han aprendido más que el oficio de la guerra y que se enfrentan a las nuevas condiciones de la posguerra y a su inserción en la vida civil ${ }^{11}$. No es una alegoría funcional para el contexto costarricense, simplemente porque no hubo una experiencia revolucionaria in situ. La mirada hacia la región debe situarse desde otro ángulo y, en ambas novelas parece articularse una mirada femenina a través de las protagonistas: Lucía, en Te llevaré en mis ojos de Rodolfo Arias y Laura, en Limón Reggae de Anacristina Rossi. El entrelazamiento del destino de naciones, mujeres y pueblos con el proceso de nation building revolucionario que teje la literatura contemporánea centroamericana, al cual hace referencia Ileana Rodríguez, se lleva hasta la fase neoliberal referida en la introducción (xxv).

Los personajes comparten un perfil: son de la misma edad, proceden de familias modestas y reaccionan frente al padre. Laura, por la apatía de éste; Lucía, por su rigidez y su machismo. Ambas pasan por un proceso de aprendizaje político que las prepara para el frente de las batallas. En Limón Reggae, Laura encuentra en su tía Maroz, de origen libanés y sinónimo de libertad, su primera mentora. Se forma políticamente en el seno del grupo afrolimonense CoRev, una agrupación con objetivos raciales afroantillanos que la educa pero no la acepta (Uno de los principales ejes de la novela es Limón y la comunidad de descendientes jamaiquinos cuya cultura con tintes británicos se marchita). Después de flirtear y decepcionarse del movimiento universitario, se compromete y luego se distancia del Partido Comunista. Al tiempo se une a la guerrilla salvadoreña. Por su parte, Lucía, el personaje de Te llevaré en mis ojos, primero se muestra apática con respecto a las actividades políticas de su novio, Gonzalo, pero termina siendo el personaje más comprometido con las revoluciones centroamericanas ${ }^{12}$. Se une a la ofensiva final de la revolución sandinista, pasa dos años trabajando en Nicaragua y luego se traslada a El Salvador, donde se mantiene activa casi hasta П1 Mackenbach y Ortiz Wallner, 88.

12 Rodolfo Arias, Tellevaré en mis ojos (San José: UNED, Legado, 2007) 109. 
el final de la lucha armada. Asimismo, a tono con la exploración de las pasiones de la literatura centroamericana contemporánea, las dos protagonistas son artistas, mujeres creativas y no miembros de un círculo intelectual, ni tampoco dirigentes de alto rango.

Mediante la afectividad de Lucía y Laura, en combate o fuera de él, en los campamentos y en los momentos de relativa tranquilidad, se establece la conexión entre Costa Rica y Centroamérica. Son mujeres jóvenes, bellas e independientes, cuyo compromiso político está íntimamente ligado a su vida sentimental. Al final del texto, Laura se siente abandonada y traicionada, lejos de los hombres a quienes amó. Su último desengaño es por Fernando, un personaje ya muy distante de aquel combatiente salvadoreño que alguna fue. Lucía, por su parte, se aleja de Gonzalo - su primer amor - por su falta de madurez y compromiso con ella y los movimientos revolucionarios. Se enamora de Alirio, combatiente salvadoreño y el padre de su niño, pero justo hacia el final de la guerra éste muere acribillado.

A fin de cuentas, lo que sostiene el tránsito de la revolución a la posguerra y mantener a ambos personajes a flote, es la maternidad. Lucía es la madre de Camilo, el niño cuya existencia impide su muerte, pues para protegerlo se queda con los suegros durante la ofensiva final. Por su parte, Laura, la protagonista de Limón Reggae, asume el papel de madre de Toño, un niñito salvadoreño que perdió a su familia durante una ofensiva. Se reencuentran años después y el enfocarse en salvarle la vida, redunda en salvarse a sí misma. Quisiera señalar que el tema de la maternidad en la novela, merece un análisis más amplio, que por espacio no abordaré. Retomando la comparación entre textos, a pesar de las similitudes, la articulación de las miradas y su intensidad difiere en las novelas.

En Limón Reggae se representa Centroamérica con Laura. Es la mirada de una compasión que se transforma en acciones concretas $^{13}$. Se podría decir que Limón Reggae se parece a Mariposa 
traicionera de Franz Galich, en el sentido de que intenta establecer ese continuum entre guerra y posguerra. Sólo que en este caso predomina el punto de vista de una mujer que quiere seguir luchando por la vida y el amor, pese a todos los desengaños. Después del fracaso de la ofensiva final y de ser testigo de la violencia de la posguerra, Laura sale de El Salvador gracias a su trabajo como intérprete. En una de sus visitas a este país, se dan cita ella y un amigo costarricense en un lugar poco seguro y allí la rapta la mara que lidera Toño, su hijo postizo desaparecido. Esas son las condiciones de su reencuentro que mencioné antes.

Presuntamente lo convence de huir hacia Costa Rica, pero cuando llegan, se da cuenta de que él tiene una agenda oculta. Laura se escapa y se marcha a Limón. Allí sus amigos la «ilustran» sobre los conductos centroamericanos de trasiego de armas y contrabando, que Carlos Cortés explota muy bien en su novela Cruz de olvido. Se evidencia así la ingenuidad de Laura por pensar que Costa Rica sigue siendo un refugio y dado el peligro inminente que corre Toño, Laura saca energía nuevamente para meterse una vez más en la boca del lobo. Es justamente en esas situaciones extremas, de fuertes polarizaciones éticas que Laura encuentra su razón de ser. Al volver nuevamente al frente para incorporarse a la ofensiva final de la guerrilla salvadoreña dice la protagonista: «Me voy al único lugar del mundo donde me he sentido viva a pesar de la muerte, donde he vivido lo mejor y lo peor, lo más alto y lo más bajo» (264). El cinismo no tiene cabida.

En Te llevaré en mis ojos es palpable la ficcionalización de la solidaridad de Costa Rica con Centroamérica, a través de Lucía. Se narran los combates en Nicaragua (R. Arias, 300-17) y posteriormente los primeros años de la victoria sandinista ${ }^{14}$. Además, se presenta al nicaragüense y al salvadoreño revolucionario. Y, a través de Alirio, se marca claramente la diferencia entre las revoluciones

14 En el marco de la solidaridad desde Costa Rica por la insurrección sandinista, resalta el papel de los guanacastecos por estar cerca; por ejemplo, don Chencho, el tornero que reemplaza una pieza clave de un cohete para uno de los combates (Arias, 314). 
de ambos países y la vida política costarricense (50), resaltando así la valentía de los combatientes ${ }^{15}$ y la actitud pseudointelectual de los jóvenes costarricenses que rodean a Lucía (129).

Sin embargo, la solidaridad con Centroamérica se desvanece cuando la pareja se desplaza a El Salvador. Flotan como espectros en la trama, hasta que se anuncia el fin de la guerra civil salvadoreña y, por tanto, la muerte de Alirio y el inesperado regreso de Lucía a Costa Rica. Durante ese lapso, la trama gira entonces en torno a las desavenencias de Mari, la amiga de Lucía y actriz venida a menos, y de Gonzalo, el ex novio, cómo logra reinventarse y convertirse en un exitoso «hombre de negocios», aunque no deje de amar secretamente a Lucía. En otras palabras, en las últimas secciones de la novela, se cuenta más bien la historia de quienes no partieron a luchar y rehacen su vida en Costa Rica. Al volver Lucía, Gonzalo recobra las esperanzas de reconquistarla y la novela termina narrando cómo se rompe el hielo durante la primera cena que comparten después una década de separación. ¿Cómo interpretar ese reencuentro entre una revolucionaria que no claudica y el yupi, desencantado, «cobarde» pero adinerado? (R. Arias, 495-97) De la solidaridad inicial y esa mirada femenina se pasa a la nostalgia del amor perdido, esta vez desde una mirada masculina.

\section{¿Se rompe el imaginario simbólico?}

Estas observaciones llevan al siguiente apartado: la discusión sobre los límites de la resignificación de la experiencia revolucionaria

15 Al respecto, véase esta cita: «Con los nicas había que aprender otra forma de ver el mundo. Eran asombrosamente emotivos, de una valentía irrestricta y de un humor imparable, poéticos de nacimiento porque esta es la patria de Rubén Darío, jodido [sic], reacios al rigor y al método, dicharacheros, endurecidos por las privaciones, dispuestos siempre a la fiesta y el trago y el abrazo con que se balancean y cantan Ay Nicaragua Nicaragüita, seguros, una y mil veces, de que esta vez va en serio y no nos pararán y el amanecer dejará de ser una tentación, como bien dirán luego los libros en las escuelas cuando empecemos la campaña de alfabetización, generosos y hospitalarios, enamorados del amor, devotos de la amistad, de la buenaventura de un corredor con mecedoras y guitarras para dejar ser la tarde» (Arias, 309). 
en el contexto costarricense y la vida cotidiana. En Te llevaré en mis ojos, mientras Lucía se encuentra fuera del país, tanto en Nicaragua como en El Salvador, no mantiene contacto con su familia. No se ficcionaliza el dolor de sus padres o su hermana ante la partida de la protagonista, es decir, se invisibiliza el impacto de su experiencia en el tejido social al limitarse únicamente a los recuerdos de Gonzalo. Cuando ella vuelve a Costa Rica, ya el movimiento revolucionario nacional ha decaído al punto de la desaparición (R. Arias, 355). Ya no hay interlocutores políticos ni misiones por cumplir. En vez de abordar el trauma de este regreso amargo, dándole oportunidad de testimoniar, de confesar, lo que ella ha vivido no lo cuenta ella; sino Mari, su amiga. El lector se entera entonces de los pormenores de la vida de Lucía y Alirio en El Salvador cuando ya está ella en Costa Rica y Alirio ha muerto. De esa manera el impacto catártico de la novela se reduce y la distancia entre la experiencia de Lucía y el lector aumenta.

Este distanciamiento es palpable en la novela en cuanto a la situación de Costa Rica y la crisis centroamericana. Si bien el narrador nos indica que el sueño utópico ha muerto y los personajes reflexionan sobre los cambios sociales, la novela no ficcionaliza el deterioro social a través de ellos o de otros personajes. Ninguno pasa por situaciones de agobio económico o desempleo, ni de violencia social. Ninguna de las consecuencias del transnacionalismo en Costa Rica la viven los personajes centrales ${ }^{16}$. Además, Centroamérica se encuentra muy lejos, tanto que los lectores nos enteramos del atentado de La Penca, en el que mueren siete personas en mayo de 1984, por medio de un periódico italiano. Rodrigo, miembro del grupo al que pertenece Lucía, es uno de esos periodistas y el periódico italiano lo está leyendo Gonzalo en su viaje de mochilero a Europa. El momento es aprovechado para hacer un recuento sobre América Central y fustigar la supuesta neutralidad costarricense.

16 El único personaje de Te llevaré en mis ojos que está en crisis es Mari, pero es crisis personal y ligada a la incapacidad para tomar decisiones maduras. Los demás, de una u otra manera, exploran el mundo o se «encarrilan» en la vida seria. 
Sin embargo, la crítica sobre Costa Rica se suscita desde el extranjero, como si la crisis centroamericana fuera parte del escenario, no una vivencia auténtica de los personajes ${ }^{17}$.

Por otra parte, la solidaridad con Centroamérica se ficcionaliza únicamente en relación con las utopías. Al llegar a Nicaragua, Lucía recuerda que le enseñaron a verlos como «paisas», «pendencieros» $\mathrm{y}\left\langle\right.$ «atrasados» ${ }^{18}$. Para contrarrestar esta actitud discriminatoria que data de fines del siglo xix, el narrador describe a los nicaragüenses encendidos por la esperanza:

Con los nicas había que aprender otra forma de ver el mundo. Eran asombrosamente emotivos, de una valentía irrestricta y de un humor imparable, poéticos de nacimiento porque esta es la patria de Rubén Darío, jodido, reacios al rigor y al método, dicharacheros, endurecidos por las privaciones, dispuestos siempre a la fiesta y el trago y el abrazo con que se balancean y cantan Ay Nicaragua Nicaragüita, seguros, una y mil veces, de que esta vez va en serio y no nos pararán y el amanecer dejará de ser una tentación, como bien dirán luego los libros en las escuelas cuando empecemos la campaña de alfabetización, generosos y hospitalarios, enamorados del amor, devotos de la amistad, de la buenaventura de un corredor con mecedoras y guitarras para dejar ser la tarde (309).

Después del traslado de Lucía y Alirio a El Salvador, no se vuelve a mencionar a los nicaragüenses de una manera tan personal. La convivencia y los aportes socioculturales de la migración nicaragüense en Costa Rica ${ }^{19}$, no se problematizan en la novela, más

17 Arias, 375-379.

18 Señala Lucía, al llegar a combatir por la revolución sandinista, que a ella le enseñaron a calificarlos de «paisas», «pendencieros» $\mathrm{y}$ «atrasados» (Arias, 309).

19 Se da en la novela una presentación de la inmigración intelectual que ha llegado a Costa Rica, desde los españoles después de la guerra civil (47), hasta los chilenos con la tradicional referencia al bar Chelles (200). No se alude, sin embargo, a la intelectualidad nica aquí. No se menciona a escritores como Sergio Ramírez, Gioconda Belli, por ejemplo, o a Carlos Martínez Rivas. Al menos, a través de los inmigrantes suramericanos y su relación con Mari se cuenta la historia del boom teatral en Costa Rica, así como su decadencia. 
que para indicar que la discriminación contra los inmigrantes nicaragüenses es una actitud aprendida incluso antes de los años setenta. Asimismo, una vez que Alirio conquista a Lucía en el campo de batalla nicaragüense, pierde su voz en la novela y Lucía recupera la suya únicamente cuando vuelve a Costa Rica. Esta relación paradójica con El Salvador ilustra los planteamientos de Ana Patricia Rodríguez, para quien la solidaridad es problemática y no es transparente, se modela críticamente por fronteras, diferencias y relaciones jerárquicas desiguales ${ }^{20}$.

En Limón Reggae la trama gira en dos espacios: Limón y la discriminación del Estado costarricense hacia dicha provincia, así como los avatares de quienes desean revitalizar su cultura; El Salvador, la guerrilla y la experiencia revolucionaria. Estratégicamente, con el fin de visibilizar ambos, desaparece el resto del territorio costarricense y sus personajes, lo cual supone un arma de doble filo. Por ejemplo, la novela cuenta, a través de Laura, las negociaciones de paz y como éstas se proyectan como instrumento para desmantelar las guerrillas y abrir el espacio para las políticas neoliberales. Es decir, se opone a la narrativa oficial que sacraliza al presidente Arias Sánchez al haber ganado el premio Nobel de la Paz (246 y siguientes). Sin embargo, no se ficcionalizan estas consecuencias en la trama, ni se integran a través de los personajes directamente o, por lo menos, simultáneamente a la experiencia de la posguerra de Laura. En consecuencia y paradójicamente, se refuerza el aislamiento costarricense frente a Centroamérica e incluso Limón.

Laura articula la ironía de la migración centroamericana hacia los Estados Unidos: «la única salida de los pobres es emigrar al país que financiaba... - (Laura) hizo un movimiento de poner billetes en la mano uno tras otro-... que financiaba su matanza $»^{21}$. Sin embargo, en la dolorosa dinámica migratoria se excluye a Nicaragua y

20 Ana P. Rodríguez, Dividing the Isthmus: Central American Transnational Histories, Literatures, and Cultures (Austin: University of Texas Press, 2009) 153.

21 Anacristina Rossi, Limón reggae. 2 ed. (San José: Editorial Legado, 2007) 278. 
la migración hacia Costa Rica, cuyos orígenes están estrechamente ligados a la provincia de Limón (consultar Sandoval). La novela de Rossi abarca la década de 1990, es decir, justo cuando se disparan la llegada de los migrantes y la discriminación. Para dar un ejemplo concreto, en la novela de Rossi, el tugurio frente al cual creció Laura es de suma importancia para la protagonista, pues allí ella vive la experiencia de «eso» entrecomillado a lo cual le puede poner palabras como adulta, es decir, a la violencia y la degradación de la vida. Si ese tugurio siguiera en pie y se retomara en las últimas páginas de la novela, sería un tugurio transnacional, habitado tanto por costarricenses como por nicaragüenses.

A diferencia de la novela de Arias, la protagonista sí articula su experiencia traumática con la guerrilla y la mara, a través de confesiones dolorosas de mujer a mujer ${ }^{22}$. En contraste, Toño como joven adulto y marero no tiene oportunidad de hacerlo. La ausencia de su voz en las últimas páginas de la novela, es una manera de ex nominación, de borramiento de su poder de gestión. El acto de solidaridad se da a medias, pues como señala Rodríguez, «The act of solidarity begins in letting others produce their own narratives out of their pain, injury, and situations... $\gg^{23}$.

\section{Conclusión}

En suma se funda un cronotopo: la participación de costarricenses en la experiencia revolucionaria centroamericana desde una mirada femenina que encuentra su salvación en el amor materno, aunque en el caso de Te llevaré en mis ojos no se mantenga esta mirada hasta el final. De esta manera, las obras se separan de la estética del cinismo y de la autodestrucción de los sujetos, tendencias literarias muy presentes en la literatura de posguerra ${ }^{24}$. Sin embargo, no logran mostrar a la sociedad

22 La primera confesión tiene lugar frente a su madre y su tía; la segunda, con Mai, una vieja amiga, en las páginas finales del libro.

23 Rodríguez, 157.

24 Beatriz Cortez, Estética del cinismo: Pasión y el desencanto en la literatura centroamericana de posguerra (Guatemala: F\&G Editores, 2010) 38. 
costarricense en el contexto transnacional. Se aísla la lucha revolucionaria tanto en Costa Rica como en El Salvador y Nicaragua, sin ahondar en el presente. Se excluye la migración y la convivencia como puntos de claves de las transformaciones regionales, mientras que el mito del pacifismo y la democracia sólo se resquebrajan. Se abre un cronotopo importante y simultáneamente hasta cierto punto se refuerza nuevamente el marco identitario épico del imaginariocostarricense ${ }^{25}$.

Más allá de la importancia de narrar la experiencia revolucionaria centroamericana, es evidente que el descentramiento como estrategia para imaginarse como un otro, en términos más colectivos ${ }^{26}$, apenas empieza en la literatura costarricense contemporánea ${ }^{27}$. Siguiendo a Carlos Cortés, estas novelas contradicen el orden establecido, las versiones de la historia oficial ${ }^{28}$, al margen de las limitaciones con respecto a los cronotopos inaugurados. A fin de cuentas, como diría Halbwachs, la memoria colectiva no se recupera, se construye en el presente.

25 Sobre Mamita Yunai señala Sandoval que al mismo tiempo que abre nuevos cronotopos, refuerza viejos límites. Se refiere a la exclusión indígena y la inclusión de los trabajadores bananeros (Sandoval García, 145).

26 Sandoval García, 324-325.

27 Talvezlas excepciones más claras son el cuento «El elefante birmano» de Uriel Quesada, en el que se narra la persecución de un joven nicaragüense por las calles de barrios bajos de Costa Rica, con lo que se marca la criminalización del inmigrante, y el monólogo «Un nica» de César Meléndez, en el que se ponen de manifiesto los prejuicios y vejaciones que sufren al querer insertarse en la sociedad costarricense. Valdría la pena explorar las razones por las que este descentramiento es mucho más visible en la producción audiovisual reciente; con esto se evidencia el peso de los materiales no impresos para las comunidades imaginadas del siglo xxi. Consultar Rodríguez (1723). Dos de las películas en las que el descentramiento juega un papel central son El camino de Yasin (2008), en la que se cuenta la historia de dos niños nicas que se vienen a Costa Rica a buscar a su mamá y De sol a sol (2005) de Jürgen Ureña, un corto sobre un matrimonio nica en Costa Rica (ella sirvienta y él guarda). Consultar Jiménez Matarrita (Cap. 5).

28 Cortés, 147-53. 